REVIEW

\title{
Endpoints of hepatitis B treatment
}

\author{
W. Chotiyaputta and A. S. F. Lok Division of Gastroenterology, Department of Internal Medicine, University of Michigan Health \\ System, Ann Arbor, MI, USA
}

Received April 2010; accepted for publication April 2010

SUMMARY. The goal of hepatitis B treatment is to prevent the development of cirrhosis, liver failure, and hepatocellular carcinoma. Ideally, clinical studies should demonstrate that hepatitis B therapies can prevent liver-related complications; however, these clinical endpoints evolve over years or decades. Therefore, clinical trials have relied on intermediate endpoints to evaluate the efficacy of treatment and to determine when treatment can be stopped. Intermediate endpoints that have been used include biochemical, histological, virological, and serological endpoints. This review will discuss the validity of these intermediate endpoints as surrogates of clinical endpoints, and the rates at which these intermediate endpoints can be achieved with currently available therapies.

Keywords: alanine aminotransferase, HBeAg seroconversion, HBsAg loss, HBV DNA, liver histology.

\section{INTRODUCTION}

The ultimate goal of chronic infectious disease treatment is the eradication of the infectious agent; however, eradication of hepatitis B virus (HBV) is not a realistic goal of hepatitis B treatment. Currently available nucleos(t)ide analogues (NUCs) act mainly as inhibitors of the reverse transcription of the pregenomic RNA to HBV DNA and have no direct effect on the covalently closed circular DNA (cccDNA) - the template for the transcription of the pregenomic RNA as well as for the translation of viral proteins. This accounts for the high rate of viral relapse when treatment is stopped. Indeed, even in persons who have serological recovery from an acute HBV infection, HBV DNA remains detectable in the liver and reactivation of $\mathrm{HBV}$ replication can occur when those persons receive immunosuppressive therapy [1]. Recent studies suggest that clearance of cccDNA relies on the turnover of infected hepatocytes $[2,3]$. This may explain the higher rate of sustained off-treatment response to interferon (IFN) therapy even though IFN has weaker antiviral activity compared to NUCs.

Abbreviations: ALT, alanine aminotransferase; Anti-HBe, hepatitis B e antibody; cccDNA, covalently closed circular DNA; CTP, ChildTurcotte-Pugh; HAI, histology activity index; HBeAg, hepatitis B e antigen; HBV, hepatitis B virus; HCC, hepatocellular carcinoma; $\mathrm{HR}$, hazard ratio; IFN, interferon; NUCs, nucleos(t)ide analogues; Peg-IFN, pegylated interferon; RCTs, randomized controlled trials; ULN, upper limit of normal.

Correspondence: Anna S. F. Lok, MD, Division of Gastroenterology, University of Michigan Health System, 3912 Taubman Center, SPC 5362, Ann Arbor 48109, MI, USA.

E-mail: aslok@med.umich.edu

\section{CLINICAL ENDPOINTS VS INTERMEDIATE (SURROGATE) ENDPOINTS}

The goal of hepatitis B treatment is to prevent the development of cirrhosis, liver failure, and hepatocellular carcinoma (HCC). These clinical endpoints take decades to evolve. Clinical trials designed to demonstrate a benefit on clinical outcomes would need to enrol hundreds or thousands of patients at risk for these events followed for many years or decades; therefore, clinical trials of hepatitis B treatment have relied on intermediate endpoints that reflect viral replication and liver disease activity as surrogates for clinical benefit. The intermediate endpoints used include virological endpoint (suppression of serum HBV DNA to undetectable by a sensitive PCR assay), serological endpoint [loss of hepatitis $\mathrm{B}$ e antigen ( $\mathrm{HBe} A g)$ with or without seroconversion to hepatitis B e antibody (anti-HBe)], biochemical endpoint [normalization of alanine aminotransferase (ALT)], as well as histological endpoint (decrease in necrosis and inflammation score by $\geq 2$ points with no worsening of fibrosis). The criteria for surrogate endpoints are summarized in Table 1.

An expert review panel questioned the validity of these intermediate endpoints as surrogates for clinical outcomes [4]. The panel cited the lack of data from randomized controlled trials (RCTs) demonstrating that achievement of the intermediate endpoints translates into decreased clinical outcomes. While data from RCTs are more vigorous, evidence supporting the validity of intermediate endpoints as surrogates for clinical outcomes can be deduced from natural history studies linking cirrhosis, liver failure, HCC, or liver-related mortality with elevated ALT, high HBV DNA, or persistent presence of $\mathrm{HBeAg}$. In addition, long-term followup studies of patients who received antiviral treatment can 
Table 1 Definition of clinical endpoints and surrogate endpoints

\begin{tabular}{|c|c|}
\hline Term & Definition \\
\hline Clinical endpoint & A characteristic or variable that reflects how a patient feels, functions, or survives \\
\hline Surrogate endpoint & $\begin{array}{l}\text { A biomarker that is intended to substitute for a clinical endpoint that should predict clinical } \\
\text { benefit or harm or lack of both }\end{array}$ \\
\hline $\begin{array}{l}\text { Criteria for surrogate } \\
\text { endpoint }\end{array}$ & $\begin{array}{l}\text { Should be easier to assess and occur more often than the corresponding clinical endpoint } \\
\text { Should be in the causal pathway to the outcome } \\
\text { The effect of an intervention on the surrogate endpoint must explain the effect on subsequent } \\
\text { clinical outcomes }\end{array}$ \\
\hline
\end{tabular}

References: [60], [61].

be used to show that patients who have intermediate responses have improved clinical outcomes. Therefore, regulatory authorities have relied on intermediate endpoints to evaluate the benefits of new HBV treatment, and professional guidelines have recommended the use of intermediate endpoints to determine treatment response and when treatment can be stopped [5-7]. This review will discuss evidence supporting the validity of the intermediate endpoints as surrogates for clinical endpoints in $\mathrm{HBV}$ treatment and the rate at which these endpoints can be achieved with currently available treatments.

\section{BIOCHEMICAL ENDPOINT}

Serum ALT is a cheap and readily available marker of liver inflammation. Phase III clinical trials of HBV treatment have included ALT normalization as an indicator of efficacy. ALT normalization has been observed in $34-51 \%$ of patients at the end of a 48-52 week course of pegylated interferon (pegIFN) with or without lamivudine and in $41-78 \%$ of patients after 1 year of NUC therapy [8-17] (Table 2). Studies of long-term NUC therapy found that ALT normalization increased to $66-80 \%$ after 5 years of treatment [18-21].

These data indicate that antiviral treatment can result in ALT normalization in most patients, but follow-up studies showed that ALT remained normal in only $32-60 \%$ of patients within 6 months of discontinuing a 1-year course of peg-IFN $[8,9,21]$ and in $32-49 \%$ of patients $6-12$ months after completing a 1-year course of NUC therapy [22,23]. Furthermore, ALT flares have been reported in 1-29\% of patients 4-6 months after completing a 1-year course of NUC therapy, and in some instances, these flares have resulted in liver failure $[11,14,15,24]$. Thus, ALT normalization, particularly if short-lived, is not a reliable surrogate of clinical outcome.

Recent data from studies of patients not receiving antiviral therapy found that persons with normal ALT can have abnormal liver histology, liver complications and liver-related deaths. These studies showed that up to $37 \%$ of persons with chronic HBV infection and normal ALT had significant inflammation and/or fibrosis on liver biopsy [25,26]. One study followed 142055 persons, aged 35-59 years for a mean of 8 years after a health examination. Compared to those with baseline ALT $<20 \mathrm{IU} / \mathrm{L}$, persons with ALT at enrolment of 20-29 IU/L and 30-39 IU/L had a 2.5-fold and eightfold risk of deaths from liver disease, respectively, for men and a 3.3-fold and 18.2-fold risk of deaths from liver disease, respectively, for women [27]. Another study of 3233 patients with chronic hepatitis B found that patients with ALT 1-2 times the upper limit of normal $(\times \mathrm{ULN})$ and those with ALT 0.5-1 $\times$ ULN had higher cumulative risks of liver complications compared to patients with ALT $<0.5 \times$ ULN [28].

Thus, data from patients not on treatment indicate that lower ALT is associated with improved clinical outcome, but decreasing ALT to the normal range defined by most clinical diagnostic laboratories may not be sufficient to prevent liver complications and liver-related deaths. These findings have led to a re-examination of the true ULN for ALT. A study of Italian blood donors suggested that the ULN for ALT should be $30 \mathrm{IU} / \mathrm{L}$ for men and $19 \mathrm{IU} / \mathrm{L}$ for women [29], while a recent study of 1105 potential liver donors in Korea all of whom had a biopsy-proven normal liver found that the ULN for ALT should be 35 IU/L for men and 26 IU/L for women [30]. Given the uncertainty regarding the upper limit for ALT in persons with normal livers, the legitimacy of ALT normalization as an intermediate endpoint is questionable.

\section{HISTOLOGICAL ENDPOINT}

Improvement in liver histology was used as the primary endpoint in many phase III clinical trials of HBV treatment because traditionally liver histology is considered to be the most accurate assessment of liver disease. In most studies, histological improvement was defined as a $\geq 2$-point decrease in the histology activity index (HAI) with no worsening of fibrosis between the pretreatment and end-of-treatment biopsies. Using this definition, histological improvement has been reported to occur in $38-48 \%$ of patients after a 1 -year course of peg-IFN treatment $[8,9]$ and in $49-74 \%$ of patients 
Table 2 Rates of intermediate endpoints during or after antiviral treatment in (a) HBeAg-positive patients (b) HBeAg-negative patients

\begin{tabular}{|c|c|c|c|c|c|c|c|}
\hline & Peg-IFN & Peg-IFN + LAM & LAM & $\mathrm{ADV}$ & ETV & $\mathrm{LdT}$ & TDF \\
\hline \multicolumn{8}{|l|}{ (a) HBeAg-positive patients } \\
\hline \multicolumn{8}{|l|}{ Responses at year 1} \\
\hline ALT normalization & $34-39(32-41)^{*}$ & $46-51(35-39)^{*}$ & $41-75(28)^{*}$ & 48 & 68 & 77 & 68 \\
\hline Histologic improvement & $22(38)^{*}$ & $33(41)^{*}$ & $49-56(34)^{*}$ & 53 & 72 & 65 & 74 \\
\hline Undetectable HBV DNA & $10-25(7-14)^{*}$ & $33-69(9-14)^{*}$ & $36-44(5)^{*}$ & 21 & 67 & 60 & 76 \\
\hline HBeAg seroconversion & $29-30(29-32)^{*}$ & $24-25(27-29)^{*}$ & $16-21(12.4-19)^{*}$ & 12 & $21(15.3)^{*}$ & 22 & 21 \\
\hline HBsAg loss & $5(3-5)^{*}$ & $7(3-7)^{*}$ & $\leq 1(0)^{*}$ & 0 & 2 & 0 & 3.2 \\
\hline \multicolumn{8}{|l|}{ Responses at year 3-5 } \\
\hline ALT normalization & $28^{\dagger}$ & $33^{\dagger}$ & 69 & 66 & 80 & 86 & N/A \\
\hline Undetectable HBV DNA & $13^{\dagger}$ & $26^{\dagger}$ & N/A & 39 & $82-94$ & $75-79$ & 95 \\
\hline HBeAg seroconversion & $35^{\dagger}$ & $25^{\dagger}$ & 47 & $37-48$ & 40 & $39-42$ & 26 \\
\hline HBsAg loss & $8^{\dagger}$ & $15^{\dagger}$ & $\mathrm{N} / \mathrm{A}$ & 2 & 6 & 2 & 8 \\
\hline \multicolumn{8}{|l|}{ (b) HBeAg-negative patients } \\
\hline \multicolumn{8}{|l|}{ Responses at year 1} \\
\hline ALT normalization & $38(59)^{*}$ & $49(60)^{*}$ & $62-78(39-44)^{*}$ & $72(32)^{*}$ & $78(49)^{*}$ & 74 & 76 \\
\hline Histologic improvement & N/A $(48)^{*}$ & N/A $(38)^{*}$ & $61-66(40)^{*}$ & 64 & 70 & 67 & 72 \\
\hline Undetectable HBV DNA & $63(19)^{*}$ & $87(20)^{*}$ & $60-73(5-7)^{*}$ & $51(8)^{*}$ & $90(3)^{*}$ & 88 & 93 \\
\hline HBsAg loss & $\mathrm{N} / \mathrm{A}(4)^{*}$ & N/A $(3)^{*}$ & $\leq 1(0)^{*}$ & $0(0)^{*}$ & $<1$ & $<1$ & 0 \\
\hline \multicolumn{8}{|l|}{ Responses at year 3-5 } \\
\hline ALT normalization & $31^{\dagger}$ & $31^{\dagger}$ & $\mathrm{N} / \mathrm{A}$ & 69 & $\mathrm{~N} / \mathrm{A}$ & 91 & N/A \\
\hline Undetectable HBV DNA & $18^{\dagger}$ & $13^{\dagger}$ & N/A & 67 & N/A & 84 & 99.1 \\
\hline HBsAg loss & $8^{\dagger}$ & $8^{\dagger}$ & $\mathrm{N} / \mathrm{A}$ & 5 & N/A & $\mathrm{N} / \mathrm{A}$ & N/A \\
\hline
\end{tabular}

Data expressed as percent.

References: [8-18], [20-23], [34,35], [38,39], [51], [62], [63], [64].

Peg-IFN, pegylated interferon; LAM, lamivudine; ADV, adefovir; ETV, entecavir; LdT, telbivudine; TDF, tenofovir, ALT, alanine aminotransferase; N/A, not available; HBeAg, hepatitis B e antigen; HBsAg, hepatitis B surface antigen; HBV, hepatitis B virus. *Data in bracket show responses 6 months after stopping treatment.

${ }^{\dagger}$ Off-treatment response.

after a 1-year course of NUC treatment [10-17] compared to $24-33 \%$ of patients who received placebo or no treatment [10-13] (Table 2). These data demonstrated that antiviral therapy can result in improvement in liver histology, but it should be noted that fibrosis scores remained largely unchanged with these short courses of treatment, and in studies of NUCs, follow-up biopsies were performed while the patients were still receiving treatment.

Studies of patients receiving longer courses of NUC showed that necrosis and inflammation continued to decrease and fibrosis regressed in patients with maintained viral suppression. One study compared liver histology pretreatment, after 1 year of lamivudine and after 3 years of lamivudine. Compared to the year-1 biopsy, further reduction in necrosis and inflammation on the year-3 biopsy was observed in $19 \%$ of patients. Of note, eight of 11 patients had regression of cirrhosis, while only one of 52 had progression to cirrhosis after 3 years of lamivudine treatment [31]. In another study of $45 \mathrm{HBeAg}$-negative patients treated with adefovir, the proportion of patients with regression of fibrosis as measured by a $\geq 1$ point decrease in Ishak fibrosis score increased from $35 \%$ at 1 year to $71 \%$ after 5 years of treatment and seven of the 12 patients (58\%) with bridging fibrosis or cirrhosis on the pretreatment biopsy had decrease in Ishak fibrosis score by $\geq 2$ points [19]. In a third study of 63 patients treated with entecavir for a median of 6 years (range $3-7$ ), a $\geq 1$ point decrease in Ishak fibrosis score was observed in $88 \%$ of the patients and cirrhosis was no longer demonstrated in three of four patients who had cirrhosis before treatment [32]. Thus, antiviral therapy has been shown not only to prevent progression of liver disease but also to reverse fibrosis.

Although liver histology is the most direct assessment of liver disease, histology is not a practical endpoint of $\mathrm{HBV}$ treatment in clinical practice. Assessment of histological endpoint will require at least two biopsies. Liver biopsy is an invasive and expensive procedure that may be associated with a small risk of serious complications. Furthermore, liver histology is not always accurate because of sampling error, particularly when the biopsy samples are small [33]. 


\section{VIROLOGICAL ENDPOINT}

Suppression of HBV replication with undetectable serum HBV DNA when tested by a sensitive PCR assay has been used as an endpoint in all clinical trials of HBV treatment. Phase III clinical trials of peg-IFN showed that virological response could be achieved in 10-69\% of HBeAg-positive and in $63-87 \%$ of HBeAg-negative patients at the end of a 1-year course of peg-IFN alone or in combination with lamivudine [8,9] (Table 2). A higher rate of virological response was observed in patients who received combination therapy of peg-IFN and lamivudine $[8,9,21]$. However, serum HBV DNA remained undetectable in only $7-14 \%$ of HBeAg-positive patients and in 19-20\% of HBeAg-negative patients 6 months after stopping treatment, and the response rates were similar in patients who received peg-IFN alone or peg-IFN plus lamivudine (Table 2). Long-term follow-up studies showed that only 19\% of HBeAg-positive patients and $15.6 \%$ of HBeAg-negative patients had sustained viral suppression 3-5 years after completing a 1-year course of peg-IFN treatment [34,35].

NUC therapy has more potent antiviral activity than IFN. Phase III clinical trials of NUCs showed that virological response could be achieved in 21-76\% of HBeAg-positive and in $51-93 \%$ of $\mathrm{HBeAg}$-negative patients at the end of a 1-year course of treatment [10-17] (Table 2). Of the five approved HBV NUCs, entecavir, telbivudine, and tenofovir were associated with higher rates of virological response, followed by lamivudine and then adefovir. Withdrawal of therapy after a 1-year course is associated with rapid viral relapse, and serum HBV DNA remained undetectable in only 5\% of HBeAg-positive patients and in $3-8 \%$ of $\mathrm{HBeAg-}$ negative patients $6-12$ months after stopping treatment $[8,9,22,23,36]$. By contrast, follow-up of patients who received long-term NUCs that have modest-high genetic barrier to resistance showed that an increasing proportion of patients achieved virological response. In a study of 125 HBeAg-negative patients who had received adefovir for 4-5 years, $72 \%$ had undetectable serum HBV DNA compared to $67 \%$ after 1 year of treatment $[13,19]$. In another study of $354 \mathrm{HBeAg-positive} \mathrm{patients} \mathrm{receiving} \mathrm{entecavir,}$ virological response increased from $67 \%$ at the end of 1 -year to $94 \%$ at the end of 5-year treatment [20]. Virological breakthrough was observed in only 28 patients (approximately 2\%/year) through the 5-year course of treatment [37]. In a third study of $176 \mathrm{HBeAg-positive} \mathrm{and}$ $250 \mathrm{HBeAg}$-negative patients receiving tenofovir, virological response increased from $76 \%$ at the end of 1 - year to $95 \%$ at the end of 3-year treatment among the HBeAg-positive patients and from $93 \%$ to $99 \%$ among the HBeAg-negative patients. Virological breakthrough was observed in only 14 patients through the 3-year course of treatment $[17,38,39]$. These studies showed that viral suppression is maintained in the vast majority of patients receiving long-term NUCs that have high genetic barrier to resistance.
The clinical benefit of treatment-related viral suppression was demonstrated in a prospective, double-blind RCT of lamivudine in 651 patients with advanced fibrosis or cirrhosis [40]. After a median of 32 months, a statistically significant difference in the incidence of the primary endpoint defined as an increase in Child-Turcotte-Pugh (CTP) score of $\geq 2$ points, variceal haemorrhage, spontaneous bacterial peritonitis, or HCC was observed between the treated patients and controls $[7.8 \%$ vs $17.7 \%$, hazard ratio (HR) $0.45,95 \%$ CI $0.28-0.73, P=0.001]$. This trial also demonstrated a statistically significant decrease in the incidence of HCC among the treated patients, $3.9 \%$ vs $7.4 \%$ in the controls $(P=0.047)$. In this study, a clinical endpoint was observed in $11 \%$ of treated patients with and in $5 \%$ of patients without lamivudine resistance mutations compared to $18 \%$ of those on placebo. The benefit of treatment-related viral suppression was also shown in a retrospective study of 656 patients (46\% had cirrhosis) who had received lamivudine for a median of 22 (range 1-66) months [41]. Among the patients with cirrhosis, HCC and death occurred less frequently in those who had maintained viral suppression compared to those with virological breakthrough. Virological response had also been shown to be associated with histologic improvement. A review of 26 prospective clinical studies of antiviral therapy involving 3428 patients who had pretreatment and post-treatment liver biopsies found that treatment-associated decrease in necrosis and inflammation was directly proportional to the reduction in serum HBV DNA levels [42].

Several large cohort studies of patients not receiving antiviral treatment have demonstrated a strong association between high serum HBV DNA level and an increased risk of developing cirrhosis, HCC, and liver-related death. In one study of 3653 hepatitis B surface antigen (HBsAg)-positive persons followed for 11.4 years in whom HBV DNA levels at baseline and the last follow-up visit were available, the adjusted HR for HCC was 4.3-5.3 (95\% CI 2.9-9.7) among those with both HBV DNA values more than 100000 copies/mL and 1.9 (95\% CI 0.8-4.4) for those with HBV DNA more than 100000 copies/mL at enrolment and $<10000$ copies/mL at the last follow-up visit, when compared to those who had HBV DNA $<10000$ copies/mL at enrolment. This study showed that persistently high serum HBV DNA was associated with an increased risk of HCC development and decrease in serum HBV DNA during follow-up was associated with a reduction in risk of HCC [43]. In another analysis of this cohort, the cumulative incidence of cirrhosis was reported to be $4.5 \%$ and $36.2 \%$ for patients with baseline HBV DNA level $<300$ copies/mL and $\geq 1000000$ copies/mL, respectively [44].

Substantial data support that persistently high serum HBV DNA is associated with an increased risk of clinical outcome and suppression of serum HBV DNA as a result of host immune response or antiviral treatment results in improved liver histology and decreased risk of clinical outcome. 
Clinical trials showed that approved treatments for hepatitis $\mathrm{B}$ are effective in suppressing HBV replication, but only a small percent of patients achieved sustained virological response when treatment is discontinued. Therefore, while virological endpoint is an important parameter of success of hepatitis B treatment, it is not a reliable surrogate for clinical outcome unless viral suppression is sustained after discontinuation of treatment or maintained during continued treatment. [22].

\section{SEROLOGICAL ENDPOINTS}

\section{Hepatitis $B$ e antigen seroconversion}

Hepatitis B e antigen seroconversion is an important endpoint in clinical trials of antiviral therapy in $\mathrm{HBeAg}$-positive patients. Phase III clinical trials showed that a 1-year course of peg-IFN resulted in HBeAg seroconversion in $24-30 \%$ of patients at the end of treatment, and addition of lamivudine did not increase the rate of HBeAg seroconversion (Table 2). $\mathrm{HBeAg}$ seroconversion was durable in most $(81 \%)$ patients after peg-IFN was stopped, and incremental HBeAg seroconversion was observed during post-treatment follow-up [34].

Phase III clinical trials showed that a 1-year course of NUC resulted in $\mathrm{HBeAg}$ seroconversion rates of $16-22 \%$ (Table 2a). The durability of NUC-induced HBeAg seroconversion has been reported to vary from 62 to $77 \%$ when treatment was stopped after 1 year $[45,46]$. Factors associated with durability of $\mathrm{HBeAg}$ seroconversion include a longer duration of consolidation therapy (12 months), younger age of the patient ( $<40$ years), HBV genotype B (vs C), and lower HBV DNA level at the time treatment was stopped [47-50]. Continued treatment with NUC resulted in increasing rates of $\mathrm{HBeAg}$ seroconversion to $26-31 \%$ after 2 years and to $40-50 \%$ after 5 years of treatment $[20,35,51]$.

Studies of patients not receiving antiviral therapy showed that presence of $\mathrm{HBeAg}$ was associated with a higher risk of development of cirrhosis and HCC. In a prospective study of 2361 HBsAg-positive men followed for 92359 person-years, those who were $\mathrm{HBeAg}$ positive at enrolment had a relative risk of HCC sixfold higher than those who were HBeAg negative [52]. Cohort follow-up studies showed that patients who underwent spontaneous HBeAg seroconversion had favourable outcome particularly if the HBeAg seroconversion occurred early in the course of chronic HBV infection and was durable, and the outcome was improved compared to patients who remained $\mathrm{HBeAg}$ positive. In one study, $88 \%$ of 223 patients who underwent HBeAg seroconversion had sustained normalization of ALT and 79\% had histologic improvement [53]. In a follow-up report of the same cohort, $66 \%$ remained as inactive carriers after a median follow-up of 25 years [54]. The 25-year probability of survival was $40 \%$ for those who remained $\mathrm{HBeAg}$ positive, $50 \%$ for those progressing to HBeAg-negative chronic hepatitis or reverting to HBeAg positive, and $95 \%$ for those whose HBeAg seroconversion was maintained. In another study, 283 patients underwent spontaneous HBeAg seroconversion. Of the 269 patients who had no evidence of cirrhosis at the time of HBeAg seroconversion, 21 developed cirrhosis during a mean follow-up of 9 years, 14 of 62 patients who progressed to HBeAg-negative hepatitis, five of nine who had HBeAg reversion, one of 14 patients who had active hepatitis of undetermined causes, and one of 184 who had sustained $\mathrm{HBeAg}$ seroconversion [55]. A third study of 483 patients followed for a mean of 11.7 years found that patients who underwent $\mathrm{HBeAg}$ seroconversion before age 30 had excellent prognosis when compared to those who did so at an older age. The cumulative incidence of cirrhosis was 3.7\%, $12.9 \%$, and $42.9 \%$ and for HCC $2.1 \%, 3.2 \%$, and $7.7 \%$ in patients who underwent $\mathrm{HBeAg}$ seroconversion before age 30 years, at age $31-40$ years and after age 40 years, respectively [56].

Follow-up studies of patients who received HBV treatment also support the use of $\mathrm{HBeAg}$ seroconversion as a surrogate marker for clinical outcome. In a study by Niederau et al., 103 patients who were treated with IFN alfa and 53 untreated controls were followed for a mean of $50.0 \pm$ 19.8 months. Fifty $(49 \%)$ of the IFN-treated patients lost HBeAg compared to 7 (13\%) of the untreated controls. Liverrelated complications occurred in $16(16 \%)$ treated patients all but one of whom failed to lose HBeAg and in 13 (25\%) controls. Survival until liver transplantation or death and lack of clinical complications was significantly better in treated patients who cleared $\mathrm{HBeAg}$ than in patients who did not $(P=0.004$ for survival and $P=0.018$ for absence of clinical complications). In another study, Lau et al. [57] followed 103 patients who received IFN treatment for a mean of 6.2 years. Patients who did not clear HBeAg had higher rates of liver-related complications and mortality $(\mathrm{HR}=13.7,95 \%$ CI 3.0-63.5) compared to those who lost HBeAg within 1 year of treatment.

These studies demonstrate that HBeAg seroconversion, spontaneous or treatment related, is associated with improvement in liver histology and clinical outcomes including survival. Therefore, HBeAg seroconversion is a valid surrogate endpoint for clinical outcome, and treatment guidelines have recommended that NUC treatment can be stopped in patients who completed at least 6- month consolidation therapy after confirmed HBeAg seroconversion. Many experts have questioned the validity of HBeAg seroconversion as an endpoint of $\mathrm{HBV}$ treatment citing that $\mathrm{HBV}$ DNA remains detectable in most patients albeit at lower levels and reactivation of HBV replication with recrudescence of hepatitis leading to progressive liver disease will ultimately occur in most patients. However, one study involving 283 patients followed for a median of 8.6 years (range, 1-18.4 years) after $\mathrm{HBeAg}$ seroconversion found that only $4.2 \%$ had HBeAg reversion and $24 \%$ developed HBeAg-negative hepatitis with detectable HBV DNA, while 


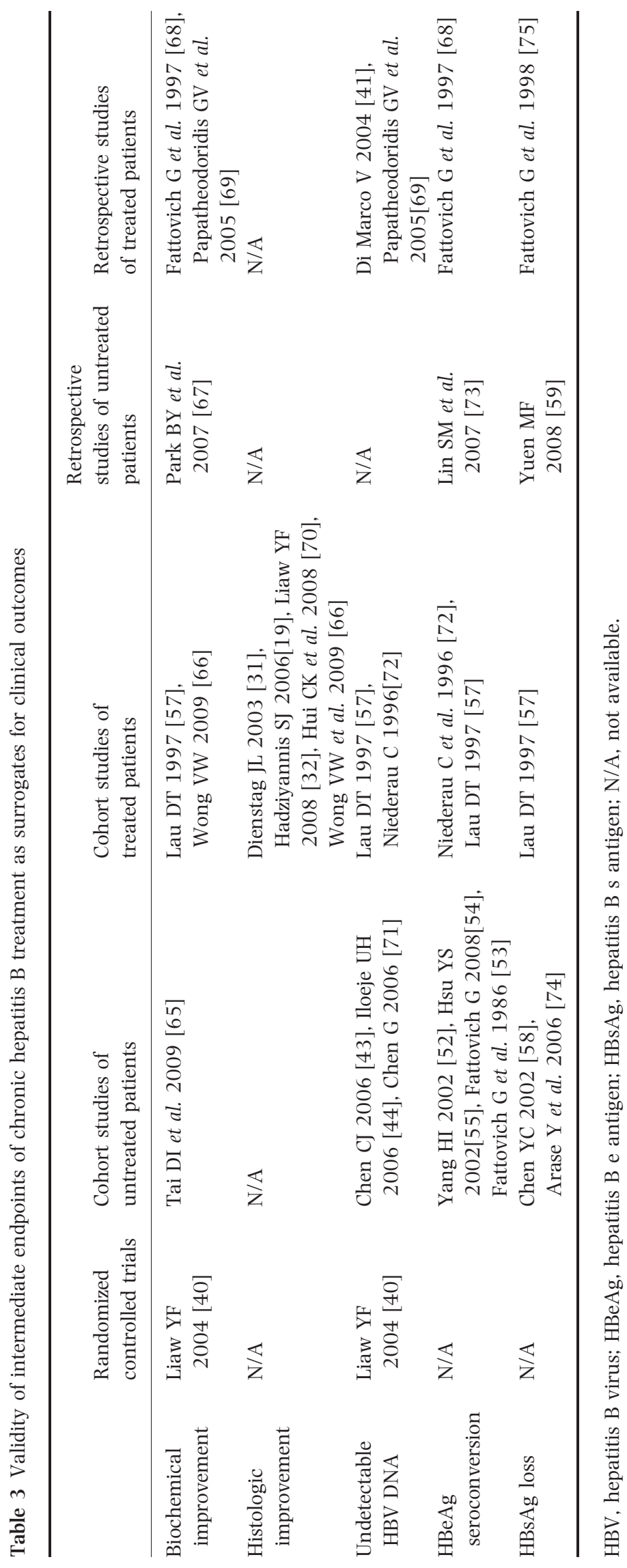

๑ 2010 Blackwell Publishing Ltd 
the other $71.8 \%$ remained in remission [55]. Given the high costs of NUCs and the risks of adverse events and antiviral resistance during long-term therapy, withdrawal of treatment in patients who have completed 12 months of consolidation therapy after confirmed HBeAg seroconversion and who have undetectable serum HBV DNA is a reasonable approach as long as the patients continue to be monitored. A recent study of patients who achieved $\mathrm{HBeAg}$ seroconversion during lamivudine treatment showed that durability of $\mathrm{HBeAg}$ seroconversion was $92 \%$ after 5 years of post-treatment follow-up among the patients who completed at least 12 months of consolidation therapy [48]. These data indicate that durable HBeAg seroconversion can be accomplished with NUC treatment.

\section{Hepatitis B surface antigen loss}

Hepatitis B surface antigen is the hallmark of HBV infection. Clinical trials showed that HBsAg loss can be observed in 5$7 \%$ of patients at the end of a 1-year course of peg-IFN with or without lamivudine $[8,9]$ and in $0-3.2 \%$ of patients at the end of a 1-year course of NUC therapy [10-17] (Table 2). Long-term follow-up of patients who received peg-IFN with or without lamivudine found that the rate of HBsAg loss increased to $8-15 \%$ in HBeAg-positive patients and $8 \%$ in HBeAg-negative patients 3 years after completion of a 1-year course of peg-IFN [34,35]. However, it should be noted that the rate of HBsAg loss was not uniform across HBV genotypes. In a study of $\mathrm{HBeAg-positive}$ patients, HBsAg loss at 3 years was observed in $28 \%$ patients with genotype A but in only $3 \%$ of patients with other HBV genotypes [34]. Another study of $230 \mathrm{HBeAg-}$ negative patients followed for 3 years after peg-IFN treatment found that HBsAg loss was observed in $9.4 \%$ of patients who had undetectable HBV DNA $(<400$ copies $/ \mathrm{mL})$ at the end of treatment compared to only $2 \%$ of those who remained viremic at the end of treatment [35]. NUCs have been reported to be associated with lower rates of HBsAg loss compared to peg-IFN. HBsAg loss has been reported to occur in $0-2 \%$ of HBeAg-positive patients and in $<1 \%$ of HBeAg-negative patients at the end of year 1 increasing to $2-8 \%$ among $\mathrm{HBeAg-positive} \mathrm{patients} \mathrm{and} \mathrm{to} 0-5 \%$ in HBeAg-negative patients after 3-5 years of continuous treatment [10-20,39] (Table 2).

Cohort studies have demonstrated that patients with chronic HBV infection who lost HBsAg spontaneously have a reduced risk of cirrhosis, HCC, and liver-related mortality compared with patients who remained HBsAg positive. In a prospective cohort study of 218 patients who were followed up for a mean of 63 months after spontaneous HBsAg clearance, of the 146 patients who had HBV monoinfection and who did not have evidence of cirrhosis at the time of HBsAg loss, none developed cirrhosis or HCC during followup compared to an incidence of cirrhosis of $3.4 \%$ and an incidence of HCC of $0.7 \%$ in those who remained HBsAg positive [58]. Another study of 298 patients found that patients with HBsAg loss before age 50 years was associated with a lower risk of HCC [59].

These data indicate that HBsAg loss is a valid surrogate for clinical outcome and a desired goal during antiviral treatment; however, except for HBV genotype A HBeAg-positive patients receiving peg-IFN therapy, the low rate of treatment-related HBsAg loss makes HBsAg loss an unrealistic endpoint in HBV treatment.

\section{CONCLUSIONS}

The goal of HBV treatment is to prevent the development of cirrhosis, HCC, and liver failure. Because clinical outcomes take decades to evolve, intermediate endpoints have to be used as surrogates to evaluate the benefits of treatment and to determine when treatment can be stopped. Data from clinical trials as well as cohort studies showed that ALT normalization and HBV DNA suppression are associated with improved clinical outcomes and are valid surrogates for assessing the benefits of treatment, but the durability of these responses is low, and these endpoints cannot be used as indicators to stop treatment (Table 3). For HBeAg-positive patients, HBeAg seroconversion is a valid clinical endpoint and can be used as an indicator for stopping NUC treatment provided that serum HBV DNA was undetectable and consolidation therapy was completed. For HBeAg-negative patients, HBsAg loss would be an ideal endpoint but the low rate at which this occurs makes it an unrealistic goal and other endpoints or predictors of sustained response after NUC treatment must be sought.

\section{ACKNOWLEDGEMENTS}

WC was supported in part by the Tuktawa Foundation (ASL) and the Siriraj Hospital, Mahidol University Foundation, Bangkok, Thailand (WC).

\section{DISCLOSURES}

W Chotiyaputta: Nothing to disclosure; Anna S. F. Lok: Receives research support from Bristol-Myers Squibb, Gilead Sciences, GlaxoSmithKline, Schering, and Roche and serves on advisory panels of Gilead Sciences, Roche Pharmaceuticals, and Bristol-Myers Squibb.

\section{REFERENCES}

1 Lok AS, Liang RH, Chiu EK, Wong KL, Chan TK, Todd D. Reactivation of hepatitis B virus replication in patients receiving cytotoxic therapy. Report of a prospective study. Gastroenterology 1991; 100(1): 182-188.

2 Summers J, Jilbert AR, Yang W et al. Hepatocyte turnover during resolution of a transient hepadnaviral infection. Proc Natl Acad Sci USA 2003; 100(20): 11652-11659. 
3 Moraleda G, Saputelli J, Aldrich CE, Averett D, Condreay L, Mason WS. Lack of effect of antiviral therapy in nondividing hepatocyte cultures on the closed circular DNA of woodchuck hepatitis virus. J Virol 1997; 71(12): 9392-9399.

4 Shamliyan TA, MacDonald R, Shaukat A et al. Antiviral therapy for adults with chronic hepatitis B: a systematic review for a National Institutes of Health Consensus Development Conference. Ann Intern Med 2009; 150(2): 111-124.

5 Lok AS, McMahon BJ. Chronic hepatitis B. Hepatology 2007; 45(2): 507-539.

6 Liaw YF, Leung N, Kao JH et al. Asian-Pacific consensus statement on the management of chronic hepatitis B: a 2008 update. Hepatol Int 2008; 2(3): 263-283.

7 European Association For The Study Of The L. EASL Clinical Practice Guidelines: management of chronic hepatitis B. J Hepatol 2009; 50(2): 227-242.

8 Lau GK, Piratvisuth T, Luo KX et al. Peginterferon Alfa-2a, lamivudine, and the combination for $\mathrm{HBeAg}$-positive chronic hepatitis B. N Engl J Med 2005; 352(26): 2682-2695.

9 Marcellin P, Lau GK, Bonino F et al. Peginterferon alfa-2a alone, lamivudine alone, and the two in combination in patients with HBeAg-negative chronic hepatitis B. N Engl J Med 2004; 351(12): 1206-1217.

10 Lai CL, Chien RN, Leung NW et al. A one-year trial of lamivudine for chronic hepatitis B. Asia Hepatitis Lamivudine Study Group. N Engl J Med 1998; 339(2): 61-68.

11 Dienstag JL, Schiff ER, Wright TL et al. Lamivudine as initial treatment for chronic hepatitis B in the United States. N Engl J Med 1999; 341(17): 1256-1263.

12 Marcellin P, Chang TT, Lim SG et al. Adefovir dipivoxil for the treatment of hepatitis $\mathrm{B}$ e antigen-positive chronic hepatitis B. N Engl J Med 2003; 348(9): 808-816.

13 Hadziyannis SJ, Tassopoulos NC, Heathcote EJ et al. Adefovir dipivoxil for the treatment of hepatitis B e antigen-negative chronic hepatitis B. N Engl J Med 2003; 348(9): 800-807.

14 Chang TT, Gish RG, de Man R et al. A comparison of entecavir and lamivudine for HBeAg-positive chronic hepatitis B. N Engl J Med 2006; 354(10): 1001-1010.

15 Lai CL, Shouval D, Lok AS et al. Entecavir versus lamivudine for patients with HBeAg-negative chronic hepatitis B. N Engl J Med 2006; 354(10): 1011-1020.

16 Lai CL, Gane E, Liaw YF et al. Telbivudine versus lamivudine in patients with chronic hepatitis B. N Engl J Med 2007; 357(25): 2576-2588.

17 Marcellin P, Heathcote EJ, Buti M et al. Tenofovir disoproxil fumarate versus adefovir dipivoxil for chronic hepatitis B. N Engl J Med 2008; 359(23): 2442-2455.

18 Marcellin P, Chang TT, Lim SG et al. Long-term efficacy and safety of adefovir dipivoxil for the treatment of hepatitis B e antigen-positive chronic hepatitis B. Hepatology 2008; 48(3): 750-758.

19 Hadziyannis SJ, Tassopoulos NC, Heathcote EJ et al. Longterm therapy with adefovir dipivoxil for HBeAg-negative chronic hepatitis B for up to 5 years. Gastroenterology 2006; 131(6): 1743-1751.

20 Chang TT, Lai CL, Kew Yoon S et al. Entecavir treatment for up to 5 years in patients with hepatitis B e antigen-positive chronic hepatitis B. Hepatology 2010; 51(2): 422-430.
21 Janssen HL, van Zonneveld M, Senturk H et al. Pegylated interferon alfa- $2 \mathrm{~b}$ alone or in combination with lamivudine for HBeAg-positive chronic hepatitis B: a randomised trial. Lancet 2005; 365(9454): 123-129.

22 Hadziyannis SJ, Tassopoulos NC, Heathcote EJ et al. Longterm therapy with adefovir dipivoxil for HBeAg-negative chronic hepatitis B. N Engl J Med 2005; 352(26): 26732681.

23 Shouval D, Lai CL, Chang TT et al. Relapse of hepatitis B in $\mathrm{HBeAg}$-negative chronic hepatitis $\mathrm{B}$ patients who discontinued successful entecavir treatment: the case for continuous antiviral therapy. J Hepatol 2009; 50(2): 289295.

24 Honkoop P, de Man RA, Niesters HG, Zondervan PE, Schalm SW. Acute exacerbation of chronic hepatitis B virus infection after withdrawal of lamivudine therapy. Hepatology 2000; 32(3): 635-639.

25 Lai M, Hyatt BJ, Nasser I, Curry M, Afdhal NH. The clinical significance of persistently normal ALT in chronic hepatitis B infection. J Hepatol 2007; 47(6): 760-767.

26 Kumar M, Sarin SK, Hissar S et al. Virologic and histologic features of chronic hepatitis B virus-infected asymptomatic patients with persistently normal ALT. Gastroenterology 2008; 134(5): 1376-1384.

27 Kim HC, Nam CM, Jee SH, Han KH, Oh DK, Suh I. Normal serum aminotransferase concentration and risk of mortality from liver diseases: prospective cohort study. BMJ 2004; 328(7446): 983-988.

28 Yuen MF, Yuan HJ, Wong DK et al. Prognostic determinants for chronic hepatitis B in Asians: therapeutic implications. Gut 2005; 54(11): 1610-1614.

29 Prati D, Taioli E, Zanella A et al. Updated definitions of healthy ranges for serum alanine aminotransferase levels. Ann Intern Med 2002; 137(1): 1-10.

30 Lee JK, Shim JH, Lee HC et al. Estimation of the healthy upper limits for serum alanine aminotransferase in Asian populations with normal liver histology. Hepatology 2010; 51: 1577-1583.

31 Dienstag JL, Goldin RD, Heathcote EJ et al. Histological outcome during long-term lamivudine therapy. Gastroenterology 2003; 124(1): 105-117.

32 Liaw YF, Chang TT, Wu SS et al. Long-term entecavir therapy results in reversal of fibrosis/cirrhosis and continued histologic improvement in patients with HBeAg (+) and (-) chronic hepatitis B: results from studies ETV-022, -027 and -901. Hepatology 2008; 48(Suppl. 1): 706A.

33 Bedossa P, Dargere D, Paradis V. Sampling variability of liver fibrosis in chronic hepatitis C. Hepatology 2003; 38(6): 1449-1457.

34 Buster EH, Flink HJ, Cakaloglu Y et al. Sustained HBeAg and HBsAg loss after long-term follow-up of HBeAg-positive patients treated with peginterferon alpha-2b. Gastroenterology 2008; 135(2): 459-467.

35 Marcellin P, Bonino F, Lau GK et al. Sustained response of hepatitis B e antigen-negative patients 3 years after treatment with peginterferon alpha-2a. Gastroenterology 2009; 136(7): 2169-2179.

36 Liaw YF, Leung NW, Chang TT et al. Effects of extended lamivudine therapy in Asian patients with chronic hepatitis 
B. Asia Hepatitis Lamivudine Study Group. Gastroenterology 2000; 119(1): 172-180.

37 Tenney DJ, Rose RE, Baldick CJ et al. Long-term monitoring shows hepatitis B virus resistance to entecavir in nucleosidenaive patients is rare through 5 years of therapy. Hepatology 2009; 49(5): 1503-1514.

38 Marcellin P, Maria B, Krastev Z et al. Three years of tenofovir disoproxil fumarate (TDF) treatment in HBeAg-negative patients with chronic hepatitis B (study 102); preliminary analysis. Hepatology 2009; 50(Suppl. 4): 532A-533A.

39 Heathcote EJ, Gane EJ, De Man RA et al. Three years of tenofovir disoproxil (TDF) treatment in $\mathrm{HBeAg}$-positive patients (HBeAg+) with chronic hepatitis B (study 103), preliminary analysis. Hepatology 2009; 50(Suppl. 4): 533A-534A.

40 Liaw YF, Sung JJ, Chow WC et al. Lamivudine for patients with chronic hepatitis B and advanced liver disease. $N$ Engl J Med 2004; 351(15): 1521-1531.

41 Di Marco V, Marzano A, Lampertico P et al. Clinical outcome of HBeAg-negative chronic hepatitis B in relation to virological response to lamivudine. Hepatology 2004; 40(4): 883-891.

42 Mommeja-Marin H, Mondou E, Blum MR, Rousseau F. Serum HBV DNA as a marker of efficacy during therapy for chronic HBV infection: analysis and review of the literature. Hepatology 2003; 37(6): 1309-1319.

43 Chen CJ, Yang HI, Su J et al. Risk of hepatocellular carcinoma across a biological gradient of serum hepatitis B virus DNA level. JAMA 2006; 295(1): 65-73.

44 Iloeje UH, Yang HI, Su J, Jen CL, You SL, Chen CJ. Predicting cirrhosis risk based on the level of circulating hepatitis B viral load. Gastroenterology 2006; 130(3): 678-686.

45 Song BC, Suh DJ, Lee HC, Chung YH, Lee YS. Hepatitis B e antigen seroconversion after lamivudine therapy is not durable in patients with chronic hepatitis B in Korea. Hepatology 2000; 32(4): 803-806.

46 Dienstag JL, Cianciara J, Karayalcin S et al. Durability of serologic response after lamivudine treatment of chronic hepatitis B. Hepatology 2003; 37(4): 748-755.

47 Ryu SH, Chung YH, Choi MH et al. Long-term additional lamivudine therapy enhances durability of lamivudine-induced HBeAg loss: a prospective study. J Hepatol 2003; 39(4): 614-619.

48 Lee HW, Lee HJ, Hwang JS et al. Lamivudine maintenance beyond one year after $\mathrm{HBeAg}$ seroconversion is a major factor for sustained virologic response in HBeAg-positive chronic hepatitis B. Hepatology 2010; 51(2): 415-421.

49 Chien RN, Yeh CT, Tsai SL, Chu CM, Liaw YF. Determinants for sustained $\mathrm{HBeAg}$ response to lamivudine therapy. Hepatology 2003; 38(5): 1267-1273.

50 Lee KM, Cho SW, Kim SW, Kim HJ, Hahm KB, Kim JH. Effect of virological response on post-treatment durability of lamivudine-induced HBeAg seroconversion. J Viral Hepat 2002; 9(3): 208-212.

51 Gish RG, Lok AS, Chang TT et al. Entecavir therapy for up to 96 weeks in patients with $\mathrm{HBeAg-positive} \mathrm{chronic} \mathrm{hepatitis}$ B. Gastroenterology 2007; 133(5): 1437-1444.

52 Yang HI, Lu SN, Liaw YF et al. Hepatitis B e antigen and the risk of hepatocellular carcinoma. N Engl J Med 2002; 347(3): 168-174.
53 Fattovich G, Rugge M, Brollo L et al. Clinical, virologic and histologic outcome following seroconversion from $\mathrm{HBeAg}$ to anti-HBe in chronic hepatitis type B. Hepatology 1986; 6(2): $167-172$.

54 Fattovich G, Olivari N, Pasino M, D’Onofrio M, Martone E, Donato F. Long-term outcome of chronic hepatitis B in Caucasian patients: mortality after 25 years. Gut 2008; 57(1): 84-90.

55 Hsu YS, Chien RN, Yeh CT et al. Long-term outcome after spontaneous HBeAg seroconversion in patients with chronic hepatitis B. Hepatology 2002; 35(6): 1522-1527.

56 Chen YC, Chu CM, Liaw YF. Age-specific prognosis following spontaneous hepatitis B e antigen seroconversion in chronic hepatitis B. Hepatology 2010; 51(2): 435-444.

57 Lau DT, Everhart J, Kleiner DE et al. Long-term follow-up of patients with chronic hepatitis B treated with interferon alfa. Gastroenterology 1997; 113(5): 1660-1667.

58 Chen YC, Sheen IS, Chu CM, Liaw YF. Prognosis following spontaneous HBsAg seroclearance in chronic hepatitis B patients with or without concurrent infection. Gastroenterology 2002; 123(4): 1084-1089.

59 Yuen MF, Wong DK, Fung J et al. HBsAg Seroclearance in chronic hepatitis B in Asian patients: replicative level and risk of hepatocellular carcinoma. Gastroenterology 2008; 135(4): 1192-1199.

60 Biomarkers Definitions Working Group. Biomarkers and surrogate endpoints: preferred definitions and conceptual framework. Clin Pharmacol Ther 2001; 69(3): 89-95.

61 Boissel JP, Collet JP, Moleur P, Haugh M. Surrogate endpoints: a basis for a rational approach. Eur J Clin Pharmacol 1992; 43(3): 235-244.

62 Chang TT, Lai CL, Chien RN et al. Four years of lamivudine treatment in Chinese patients with chronic hepatitis B. J Gastroenterol Hepatol 2004; 19(11): 1276-1282.

63 Hsu CW, Chen YC, Liaw YF et al. Prolonged efficacy and safety of 3 years of continuous telbivudine treatment in pooled data from Globe and 015 studies in chronic hepatitis B patients. J Hepatol 2009; 50(Suppl. 1): S331.

64 Wang Y, Thongsawat S, Gane EJ et al. Efficacy and safety outcomes after 4 years of telbivudine treatment in patients with chronic hepatitis B (CHB). Hepatology 2009; 50(Suppl. 4): 533A.

65 Tai DI, Lin SM, Sheen IS, Chu CM, Lin DY, Liaw YF. Longterm outcome of hepatitis B e antigen-negative hepatitis B surface antigen carriers in relation to changes of alanine aminotransferase levels over time. Hepatology 2009; 49(6): 1859-1867.

66 Wong VW, Wong GL, Chim AM et al. Surrogate end points and long-term outcome in patients with chronic hepatitis B. Clin Gastroenterol Hepatol 2009; 7(10): 11131120.

67 Park BK, Park YN, Ahn SH et al. Long-term outcome of chronic hepatitis B based on histological grade and stage. J Gastroenterol Hepatol 2007; 22(3): 383-388.

68 Fattovich G, Giustina G, Realdi G, Corrocher R, Schalm SW. Long-term outcome of hepatitis B e antigen-positive patients with compensated cirrhosis treated with interferon alfa. European Concerted Action on Viral Hepatitis (EUROHEP). Hepatology 1997; 26(5): 1338-1342. 
69 Papatheodoridis GV, Dimou E, Dimakopoulos K et al. Outcome of hepatitis B e antigen-negative chronic hepatitis B on long-term nucleos(t)ide analog therapy starting with lamivudine. Hepatology 2005; 42(1): 121-129.

70 Hui CK, Leung N, Shek WH et al. Changes in liver histology as a "surrogate" end point of antiviral therapy for chronic HBV can predict progression to liver complications. J Clin Gastroenterol 2008; 42(5): 533-538.

71 Chen G, Lin W, Shen F, Iloeje UH, London WT, Evans AA. Past HBV viral load as predictor of mortality and morbidity from HCC and chronic liver disease in a prospective study. Am J Gastroenterol 2006; 101(8): 1797-1803.

72 Niederau C, Heintges T, Lange S et al. Long-term follow-up of $\mathrm{HBeAg}$-positive patients treated with interferon alfa for chronic hepatitis B. N Engl J Med 1996; 334(22): 14221427.

73 Lin SM, Yu ML, Lee CM et al. Interferon therapy in HBeAg positive chronic hepatitis reduces progression to cirrhosis and hepatocellular carcinoma. J Hepatol 2007; 46(1): 4552.

74 Arase Y, Ikeda K, Suzuki F et al. Long-term outcome after hepatitis B surface antigen seroclearance in patients with chronic hepatitis B. Am J Med 2006; 119(1): 71.e9-71.e16.

75 Fattovich G, Giustina G, Sanchez-Tapias J et al. Delayed clearance of serum HBsAg in compensated cirrhosis B: relation to interferon alpha therapy and disease prognosis. European Concerted Action on Viral Hepatitis (EUROHEP). Am J Gastroenterol 1998; 93(6): 896-900. 